BULLETIN Bulletin hispanique

HispaniquE Université Michel de Montaigne Bordeaux

$110-2 \mid 2008$

Varia

\title{
La obra narrativa de Enrique Vila-Matas
}

entre la poética del silencio y la escritura infinita

Teresa Gómez Trueba

\section{(2) OpenEdition}

Journals

Edición electrónica

URL: http://journals.openedition.org/bulletinhispanique/779

DOI: $10.4000 /$ bulletinhispanique. 779

ISSN: 1775-3821

Editor

Presses universitaires de Bordeaux

Edición impresa

Fecha de publicación: 1 diciembre 2008

Paginación: 537-558

ISBN: 978-2-86781-543-0

ISSN: 0007-4640

Referencia electrónica

Teresa Gómez Trueba, "La obra narrativa de Enrique Vila-Matas », Bulletin hispanique [En línea],

110-2 | 2008, Publicado el 01 diciembre 2011, consultado el 20 abril 2019. URL : http://

journals.openedition.org/bulletinhispanique/779 ; DOI : 10.4000/bulletinhispanique.779 


\title{
La obra narrativa de Enrique Vila-Matas: entre la poética del silencio y la escritura infinita
}

\author{
Teresa Gómez Trueba \\ Universidad de Valladolid - España
}

Cet article propose une analyse de l'ouvre narrative de Enrique Vila-Matas sous l'angle de la réflexion métalittéraire qu'elle mène en permanence. Plus encore, l'article tient compte du fait que cette ouvre remet en question le mythe ou l'utopie littéraire d'un livre infini qui puisse rendre compte de la totalité de l'Univers, présents chez des écrivains aussi fondamentaux que Borges ou Calvino.

En este artículo se estudia la obra narrativa de Enrique Vila-Matas, atendiendo a su permanente reflexión metaliteraria y fundamentalmente a la revisión que se hace en su obra del mito o utopia literaria del libro infinito que da cuenta de la totalidad del Universo, tan importante en autores fundamentales del siglo XX como Borges o Calvino.

This article proposes to analyze Enrique Vila-Matas' narrative work, under the angle of his constant meta-literary reflection. Moreover, it takes into account the fact that this work questions the literary myth or utopia of an infinite book that would account for the whole Universe, a theme present in twentieth century writers as fundamental as Borges or Calvino.

Mots-clés : Novela española contemporánea - Enrique Vila-Matas - poética del silencio - escritura infinita.

$B H i$, Tome 110, n $^{\circ} 2$ - décembre 2008 - p. 537 à 558. 
T os novelistas Enrique Vila-Matas y Roberto Bolaño han coincido en citar en sus escritos una famosa escena cinematográfica: Vila-Matas lo hace en un ensayo titulado "Un tapiz que se dispara en muchas direcciones» ${ }^{1}$ y Bolaño en su novela Los detectives salvajes ${ }^{2}$. Se trata de aquélla de la película de Stanley Kubrick El resplandor, en la que el novelista loco, interpretado por Jack Nicholson, hace creer a su familia que trabaja sin descanso en la escritura de una novela, cuando su mujer descubre horrorizada que a lo largo de varios meses su marido se ha dedicado a repetir una y otra vez una única frase hasta el infinito. Que ambos escritores, a veces comparados por la crítica, nos hayan llamado la atención sobre la misma escena no me parece casual. Los dos parecen haber visto en ella una extraordinaria metáfora del mito literario de la escritura sin fin, la escritura por la escritura que se prolonga de manera obsesiva e irremediable lo que dura la vida del escritor. Como veremos, la concepción de la escritura como fuga sin retorno hacia el infinito es aludida en numerosas ocasiones en la obra de Enrique Vila-Matas. Según declara el propio autor en una entrevista, concibe su propia escritura como «un viaje sin retorno [...] un viaje al fin de la noche» ${ }^{3}$. El motivo argumental del viaje sin retorno, la odisea rectilínea y sin Ítaca que transforma a un individuo que ya no regresa a casa, no es sólo el argumento de una de las novelas de Vila-Matas, El viaje vertical ${ }^{4}$, sino también uno de los conceptos clave de toda su concepción estética.

Enrique Vila-Matas cuenta ya con una obra de extensión considerable y con una cada vez mejor acogida por parte de crítica y lectores. Se trata para algunos del novelista más original e interesante del actual panorama narrativo español ${ }^{5}$. Aunque escasas, también ha recibido críticas negativas, que fundamentalmente acusan a sus novelas de excesivamente reiterativas y obsesivas, y de cultivar un discurso que tiende irremediablemente al agotamiento, al haber renunciado a contar cosas para alimentarse única y exclusivamente de sí mismo ${ }^{6}$. Es cierto que cada una de las novelas de Vila-Matas trata una y otra vez unos mismos temas, que su obra ha ido

1. E. Vila-Matas, "Un tapiz que se dispara en muchas direcciones», en Desde la ciudad nerviosa, Madrid, Alfaguara, 2004 (1 $1^{\text {a }}$ ed.: 2000), p. 194.

2. R. Bolaño, Los detectives salvajes, Barcelona, Anagrama, 2004 (1ª ed.: 1998), p. 523.

3. E. Vila-Matas, «Encuentro digital con Enrique Vila-Matas» (http://www.el-mundo.es/ encuentros/invitados/2002/12/568/) [en línea].

4. Barcelona, Anagrama, 1999.

5. Vid., por ejemplo, los trabajos reunidos en el monográfico que le dedica Cuadernos de narrativa, Universidad de Neuchâtel, 7, diciembre 2002.

6. Vid., sobre todo, V. L. Mora, «La literatura del agotamiento» [Reseña de E. Vila-Matas, Doctor Pasavento, Barcelona, Anagrama, 2005] (http://vicenteluismora.bitacoras.com/) [en línea]. 
evolucionando hacia un discurso en el que progresivamente tiene menor importancia el referente externo, de manera que ya el argumento se adelgaza (sin llegar nunca a desaparecer del todo) hasta extremos desconcertantes, como ocurre en su última novela Doctor Pasavento. Pero, precisamente, esa vuelta obsesiva, libro tras libro, una y otra vez, al mismo asunto, alejándose y acercándose a él reiteradamente, como si estuviera recorriendo un laberinto del que todavía no ha logrado encontrar la salida, es lo que convierte toda la obra de Vila-Matas en un proyecto compacto y sumamente coherente, que adquiere mayor sentido y valor considerado en conjunto. Cada uno de sus libros ha supuesto una nueva vuelta de tuerca dentro de una prolongada reflexión en torno a la eterna (y no por ello agotada) cuestión del arte de la novela y la representación literaria. Reflexión que lejos de haberse debilitado permanece en sus últimas novelas, alcanzando su momento más álgido e interesante.

Estamos ante uno de esos escritores cuya obra pone de continuo el dedo en la llaga del problema teórico en torno a los límites del concepto de novela. Las novelas de Vila-Matas se sitúan siempre en las fronteras del género, convirtiéndose en una narración del problema que se le plantea al escritor respecto a las convenciones estéticas que coartan su expresividad. En varias ocasiones el propio autor se ha manifestado con claridad sobre este asunto, confesándose afín a cierta tendencia de la literatura actual, en la que inscribe, entre otros, a Los anillos de Saturno de Sebald, Microcosmos de Magris, El arte de la fuga de Pitol, o a Tabucchi y su Dama de Porto Pim. Partiendo de la convicción de que la vida es "un tejido continuo», entienden todos ellos que la novela debe dar cuenta de ese enramado, convirtiéndose en un «tapiz que se dispara en muchas direcciones: material ficcional, documental, autobiográfico, ensayístico, histórico, epistolar, libresco... Son libros que mezclan la narración con la experiencia, los recuerdos de lecturas y la realidad traída al texto como tal» ${ }^{7}$. Conecta asimismo su idea de la novela como un tapiz con el concepto de «multiplicidad» de Calvino: la novela como enciclopedia que se presenta como «red de conexiones entre los hechos, entre las personas, entre las cosas del mundo» ${ }^{8}$. En su última novela, Doctor Pasavento, cita a Laurence Sterne como inventor (o reinventor, ya que a su vez partía de Cervantes y Montaigne) de un género literario que habría que relacionar con todo esto, la novela-ensayo, con su peculiar tratamiento de las

7. E. Vila-Matas, "Un tapiz que se dispara en muchas direcciones», art. cit., pp. 192 y 202.

8. I. Calvino, "Multiplicidad», en Seis propuestas para el próximo milenio, Madrid, Siruela, 1989, pp. 115-138, p. 121. 
relaciones entre realidad y ficción, aunque mucha gente considere que es esta una invención fundamental de nuestros días (Doctor Pasavento, p. 44).

Esa novela-ensayo que practica Vila-Matas surge en íntima relación con la crisis de la representación literaria, que aunque no nueva, sí se ha agudizado en el siglo XX. El propio autor ha declarado en una entrevista que «no puede existir ya buena literatura si en ésta no hay implícita de fondo una reflexión que cuestione incluso la posibilidad o la noción misma de la literatura» ${ }^{9}$. Esa obsesión por el posible agotamiento de la literatura lo convierte, a decir de la crítica, en un novelista of the exhaustion, según la expresión de John Barth en su célebre artículo de $1967^{10}$. Por un lado está el problema de que ya todo está escrito. En París no se acaba nunca, cuenta el narrador que cuando estaba terminando su novela La asesina ilustrada se había enterado de que Agatha Christie ya había escrito una novela, El asesino de Roger Ackroyd, con el mismo supuesto rasgo original: que el asesino era el narrador y que se lo revelaba al lector en el último momento ${ }^{11}$. Pero hay otra cuestión aún más dramática que Vila-Matas no ha dejado de abordar en todas sus obras: la imposibilidad de representar el mundo a través de la escritura. Así, también en París no se acaba nunca se pregunta directamente si existe realmente lo real o si de verdad se puede ver algo de verdad. La conclusión es que nuestros ojos no pueden alcanzarlo con la vista: «el infinito campo de los posibles se extiende y, si por casualidad, lo real se presentara ante nosotros quedaría tan fuera de los posibles que, en un brusco desmayo, iríamos a dar contra ese muro surgido de repente y nos caeríamos pasmados» (p. 34). Por supuesto, es la suya una actitud escéptica que en principio parece exponer el problema, sin ninguna esperanza de resolverlo. Como casi todos los escritores que admira Vila-Matas y que cita continuamente en sus novelas, estamos ante uno de esos autores que no ofrecen soluciones ni palabras de consolación, sino interrogaciones.

Ya hace mucho tiempo que la novela cuestionó la eficacia de las grandes tramas y el concepto tradicional de «realidad», al considerarlo insuficiente para dar cuenta de un mundo complejo, caótico y desordenado, regido por las leyes del azar. No sólo no se ha detenido la reflexión sobre esa situación, sino que obras como la de Vila-Matas se han ido construyendo a partir de

9. I. Echevarría, «Enrique Vila-Matas: "Un escritor solemne es lo menos solemne que hay"”, El País. Babelia, n 430, 19 de febrero de 2000, p. 7. Vid. D. Roas, «El silencio de la escritura (a propósito de Bartleby y compañia)", Cuadernos de narrativa, Grand Séminaire, Universidad de Neuchâtel, 2 y 3 de diciembre de 2002, 7, diciembre 2002, pp. 129-139, p. 129.

10. D. Ródenas de Moya, "La novela póstuma o el mal de Vila-Matas», Cuadernos de narrativa, Grand Séminaire, Universidad de Neuchâtel, 2 y 3 de diciembre de 2002, 7, diciembre 2002, pp. 141-158, p. 145.

11. E. Vila-Matas, París no se acaba nunca, Barcelona, Anagrama, 2003, p. 218. 
la misma. A medida que ha ido avanzando y creciendo su obra narrativa, parece acentuarse el descrédito ante la posibilidad de explicar el mundo a través de un discurso totalizador, así como la búsqueda de modelos narrativos alternativos. "Ya que se han perdido todas las ilusiones de una totalidad representable, hay que reinventar nuestros propios medios de representación» ${ }^{12}$, declara el narrador de Bartleby y compañía. Por su parte, el narrador de El mal de Montano afirma que «el mundo se halla desintegrado, y sólo si uno se atreve a mostrarlo en su disolución es posible ofrecer de él alguna imagen verosímil» ${ }^{13}$.

Esta constante reflexión sobre la imposibilidad de representar el mundo ha conducido a este autor a una de sus mayores obsesiones: la poética del silencio. Bartleby y compañía es un muestrario de escritores que han decidido dejar de escribir, los «escritores del No». También en su última obra, Doctor Pasavento, se plantea una y otra vez el único fin hacia el que puede encaminarse hoy en día la literatura: "Va hacia sí misma, hacia su esencia, que es la desaparición» ${ }^{14}$. El único modo de ir más allá es desaparecer: «Desaparecer, ése era el gran reto. Se trataba de no olvidar que yo siempre había pensado que hay que intentar ser infinitamente pequeño, que seguramente es la perfección misma» (Doctor Pasavento, p. 41).

Estamos por tanto ante un tipo de literatura que aclama una y otra vez, en el caso de Vila-Matas de manera obsesiva y muy reincidente, el silencio como única salida posible. Ahora bien, muchas veces se ha llamado la atención acerca de la situación contradictoria de este tipo de literatura que utiliza el lenguaje para decir que el lenguaje y por tanto la literatura no funcionan ${ }^{15}$. En esta continua contradicción se sitúa la obra de Vila-Matas, existiendo en ella un permanente vaivén, una tensión aún no resulta, y que probablemente nunca lo esté, entre el anhelo del silencio y la necesidad irrevocable de expresar con el lenguaje ese mismo anhelo. Así, los sucesivos narradores de sus novelas, en la mayoría de los casos novelistas en situación de crisis (Extraña forma de vida, El viaje vertical, Bartleby y compañia, El mal de Montano, París no se acaba nunca, Doctor Pasavento), no dejan de ensayar diferentes caminos en la persecución de una salida para sus obras, de una revelación, y en ese empeño perderán mil veces el camino, tropezando a cada instante. Se declaran conocedores de que no existen absolutos, de que toda verdad es relativa y huidiza, pero no por ello desisten de buscarla. Y con esa búsqueda se va formando una trama, trama que aunque leve y discontinua

12. E. Vila-Matas, Bartleby y compañia, Barcelona, Anagrama, 2000, p. 169.

13. E. Vila-Matas, El mal de Montano, Barcelona, Anagrama, 2002, p. 222.

14. E. Vila-Matas, Doctor Pasavento, Barcelona, Anagrama, 2005, p. 20.

15. D. Roas, art. cit., p. 132. 
existe en todas las novelas citadas. Curiosamente, casi todas ellas ofrecen la trama de un narrador (que a su vez es novelista) que no cree en tramas. En definitiva, la trama, la historia, les sirve a escritores como Vila-Matas como soporte necesario para poner en evidencia su irrealidad. Unas palabra de otro escritor, al que precisamente Vila-Matas considera un maestro, Sergio Pitol, creo que podrían ser también aplicables a su escritura: «En mi caso el interés por lo nuevo jamás logró mitigar mi pasión por la trama. Sin ella la vida me ha parecido siempre disminuida. Contar cosas reales y deshacer y al mismo tiempo potenciar su realidad ha sido mi vocación» ${ }^{16}$.

El silencio y la escritura están íntimamente conectados como la Nada lo está con el Todo, o como la realidad de la historia con su irrealidad. Lo uno siempre conduce a lo otro. Así, tal y como se declara en Bartleby y compañia, existe el sindrome de Bartleby, del escritor que no escribe, pero también el sindrome de Bartleby al revés, del que no puede dejar de escribir, y ambos síntomas están íntimamente relacionados ${ }^{17}$ :

Hay un punto en común entre los desmesurados Gadda y Musil: ambos tenían que abandonar sus libros porque estos se les volvían infinitos, los dos acababan viéndose obligados a poner, sin desearlo, un punto final a sus novelas, cayendo en el síndrome de Bartleby, cayendo en un tipo de silencio que detestaban: ese tipo de silencio en el que, dicho sea de paso, y salvando todas las insalvables distancias, voy a tener que caer yo, tarde o temprano, me guste o no, ya que sería iluso, por mi parte, ignorar que estas notas cada vez se parecen más a esas superficies de Mondrian llenas de cuadrados, que sugieren al espectador la idea de que rebasan el lienzo y buscan -faltaría más- encuadrar el infinito, que es algo que, si como creo ver estoy ya haciendo, me va a obligar a la paradoja de, valiéndome de un solo gesto, eclipsarme (Bartleby y compañia, pp. 155-156).

El afán de abarcarlo Todo en la escritura conduce a la Nada, al silencio definitivo, a la desaparición. Pero el camino también se recorre en sentido contrario: del silencio a la escritura sin fin, o dicho con dos conceptos críticos calvinianos que nuestro autor ha utilizado también en sus crónicas, de la «levedad» a «la multiplicidad ${ }^{18}$.

16. S. Pitol, El arte de la fuga, Barcelona, Anagrama, 1997, p. 174.

17. E. Vila-Matas, Bartleby y compañía, Barcelona, Anagrama, 2000, pp. 153-154.

18. I. Calvino, «Levedad» y "Multiplicidad», en Seis propuestas para el próximo milenio, op. cit., pp. 13-41 y pp. 115-138. D. Roas identifica también la escritura de Vila-Matas con 
El propio Vila-Matas, a partir de un comentario de la novela Los detectives salvajes del arriba citado Roberto Bolańo y de un supuesto parecido que la crítica achaca a esta obra con la suya, reflexiona acerca de la relación existente entre esos dos valores de la literatura del milenio que señaló Calvino: la levedad y la multiplicidad. El resultado de esa indagación es que curiosamente, y tal y como vengo planteando en este artículo, ambas están íntimamente relacionadas, y que su escritura pasa de continuo de la una a la otra o, mejor dicho, comparte simultáneamente ambos valores. En primer lugar identifica a Bolaño, y concretamente su extensa novela Los detectives salvajes, de 610 páginas, donde se representa el mundo como un complicado sistema de relaciones en una estructura que tiende al infinito, con el arte de la multiplicidad. Pero a medida que Vila-Matas escribe su comentario de la obra de Bolaño, nos explica también cómo ve él su propia escritura, revelándosele entonces la contradicción en la que cae inevitablemente su poética. Dice que en principio se había considerado a sí mismo novelista afín a otro de los valores señalados por Calvino, y aparentemente opuesto al de la multiplicidad: la levedad, lo que para su tranquilidad le separaba supuestamente de Bolaño. Frente a las largas novelas de Bolaño, él, autor de obras más cortas, pertenecería supuestamente al grupo de escritores de la brevedad, pero enseguida se da cuenta de que no es así:

En el Bolaño de Los detectives salvajes hay algo de desesperación maniática. Escribo esto y me pregunto si en realidad el desesperado maniático no seré yo. Quería hablar con levedad y la máxima agilidad de la extravagancia y del efervescente magma lingüístico de la novela de Bolaño [...] y ahora me doy cuenta de que llevo ya bastantes folios y que el desesperado maniático soy yo, que escribiendo sobre Bolaño me he convertido en un escritor del casillero calviniano de la multiplicidad. [...] heme aquí convertido en un hombre que ha quedado enredado en el mundo de la multiplicidad de Bolaño, ese escritor que ve el mundo como un enredo, una maraña o un ovillo ${ }^{19}$.

Paradójicamente, esa indagación continua sobre la imposibilidad de representar el mundo a través de la escritura desemboca en una escritura infinita, que no sólo es puesta en práctica por el autor, sino que termina por convertirse en otro de los temas y obsesiones de su particular mundo literario.

los valores postulados por Calvino de «levedad»y «multiplicidad» (art. cit., pp. 137-138).

19. E. Vila-Matas, «Bolaño en la distancia», en Desde la ciudad nerviosa, op. cit., pp. 275284 , p. 280. 
En una entrevista dijo Vila-Matas: "Hay un verso que dice "en el centro del vacío hay otra fiesta”, en esa otra fiesta se reúnen los suicidas, los shandys, los montanianos, los bartlebys y otros figurantes de mi escena literaria. Algún día acudiré a esa fiesta, cuando la obra esté completada ${ }^{20}$. Mientras se llegue a ese ansiado "centro del vacío», se trata de seguir escribiendo sin descanso, y al escribir seguir pasando revista a las diferentes soluciones que la historia de la literatura y otros autores admirados por él han dado a esta cuestión.

\section{Caminos hacia lo infinito en literatura}

Ya hace muchos años que Umberto Eco advirtió como rasgo esencial del arte occidental que nunca aceptará perderse o disolverse en la contemplación de la multiplicidad y el caos del mundo, sino que se perderá siempre tratando de dominarlo y recomponerlo, sin renunciar a definirlo nuevamente a través de las leyes de la probabilidad y la estadística ${ }^{21}$. «El orden y la inteligencia que distingue constituyen su vocación», dice finalmente $\mathrm{Eco}^{22}$.

Muchos han sido los procedimientos ensayados para dar cuenta de esa infinitud del mundo. Junto a aquellos autores que renuncian a concluir o incluso a realizar la obra (como los bartlebys de Vila-Matas), entendiendo que lo acabado en su finitiud y limitación nunca podrá dar cabida a las infinitas posibilidades del mundo (de los que luego nos ocuparemos), hay que situar a aquellos otros esforzados en hallar la metáfora o representación perfecta de esa multiplicidad de posibilidades del universo. Partiendo del hecho de que el infinito, entendido como totalidad, se escapa a nuestro limitado entendimiento, el hombre, y en este caso el escritor, se ve en la necesidad de construir en su intelecto la representación del infinito como entidad cerrada por medio de construcciones simbólicas ${ }^{23}$. Siguiendo a Santos Unamuno y su definición de lo que denomina "poética de la totalidad», me refiero a aquellos que se dedican a la construcción de textos que funcionan metafóricamente como modelos del universo, construcciones literarias finitas, caracterizadas muchas veces, aunque no necesariamente, por la brevedad «que condensan y evocan las infinitas posibilidades de la

20. E. Vila-Matas, «Encuentro digital con Enrique Vila-Matas» (http://www.el-mundo. es/encuentros/invitados/2002/12/568/) [en línea], p. 2.

21. U. Eco, Obra abierta, Barcelona, Ariel, 1984, p. 273.

22. Ibid., p. 274.

23. Vid. E. Santos Unamuno, Laberintos de papel: Jorge Luis Borges e Italo Calvino en la era digital, Cáceres, Universidad de Extremadura, 2002, p. 44. 
realidad ya sea por medio de las estructuras narrativas o poéticas mismas del texto, ya sea a través de la inclusión en la obra de símbolos de la totalidad potencial (entidades totales), valiéndose de una concepción combinatoria de la realidad y de la literatura ${ }^{24}$. Por supuesto, en esa tradición habría que situar, aparte de algunos precedentes como Mallarmé y la concepción de su Livre, la obra de autores como Borges o Calvino, ambos citados con frecuencia por Vila-Matas.

Respecto al primero, en París no se acaba nunca el narrador no sólo enumera todas las deudas que su pensamiento tiene contraído con Borges (pp. 193-195), sino que incluso llega a afirmar que a Borges deben los modernos nada menos que la posibilidad de seguir escribiendo (p. 195). Poco hay que decir a estas alturas de los populares símbolos utilizados por Borges como representación de la totalidad del Universo: junto al Aleph o el Zahir, la moneda total que presupone en sí misma la historia universal y el mundo, recuérdese el poeta que aparece en "El espejo y la máscara», que escribe composiciones cada vez más breves, hasta llegar a un poema de una sola línea en el que se encierra el universo, o el relato titulado "Undr», que va aún más allá respecto al anterior, concibiendo una totalidad encerrada en esa palabra $^{25}$. Símbolos que, sin duda, representan a la perfección esa tensión dialéctica entre el silencio y la escritura de la que venimos hablando.

Durante los años 60-70, un camino frecuente para conseguir esa representación ha sido la recurrencia de sistemas combinatorios que se multiplican internamente evocando en el lector la idea de totalidad. Y ahí habría que situar, entre otros, los experimentos de narrativa combinatoria del grupo OULIPO, la obra de Italo Calvino (El castillo de los destinos cruzados, Si una noche de invierno un viajero, etc.) o la de algunos de sus compañeros de generación como Georges Perec o Raymond Queneau. También a esos anhelos de representar simbólicamente la totalidad del universo habría que sumar otras muchas estrategias narrativas de vieja tradición, como la de las cajas chinas o mise en abîme, o todas las variantes del concepto de hipernovela descrito por el mismo Calvino en su famoso ensayo sobre la presencia de la «multiplicidad» en la literatura del milenio que acaba de comenzar ${ }^{26}$. No obstante, hay que advertir que en todos estos proyectos casi siempre asoman las sospechas del fracaso de semejante utopía. El mismo Borges se anticipó al mostrarse ya escéptico ante la evidencia del carácter cerrado

24. Ibid., p. 50.

25. Ibid., p. 52.

26. Vid. mi artículo «El mundo hecho pedazos: multiplicidad en la novela y el cine contemporáneos", ALEC. Anales de la Literatura Española Contemporánea, 31, 1, 2006, pp. 93-118. 
de cualquier proyecto combinatorio ${ }^{27}$. Aunque, empujadas por un anhelo de representar el infinito actual y simultáneo, las obras pretendidamente abiertas y potenciales que resultan de estos proyectos no dejan por ello de ser finitas y limitadas.

Cabe otra posibilidad y es aquella que se sustenta en la creencia de que el único orden que puede imponer el hombre a la situación en que se encuentra es, precisamente, la organización estructural desordenada que permita una toma de conciencia de la situación. Así, frente a la poética de la totalidad, existe otra tentativa de dar cuenta de la infinitud del mundo, lo que el mismo Vila-Matas ha definido como "el arte del extravío" (Bartleby y compañia, p. 57) o el simple "parloteo» (Doctor Pasavento, p. 153). En su última novela, Doctor Pasavento, a propósito de Sterne, habla de la novela construida, casi en su totalidad, con digresiones. Y considera que la divagación o digresión es una estrategia perfecta para conseguir ese efecto de tiempo ilimitado. Al aplazar la conclusión, multiplica el tiempo en el interior de la obra, en una fuga perpetua (p. 44).

Podríamos relacionar todo esto también con lo que Ricardo Piglia ha llamado «arte de la interrupción» o "arte de la interferencia». Se trata de convertir precisamente aquello que impide llegar al destino, deteniendo el tiempo del relato, en el registro y la esencia de la escritura. Considera a Kafka (por supuesto, otro de los referentes literarios continuos de Vila-Matas) el gran genio de este arte. Kafka se interrumpe de pronto, dejando la frase sin terminar y luego empieza de nuevo sin retomar las cosas donde habían quedado. Pero tampoco tacha la frase interrumpida, sino que la deja tal cual, haciendo así visible que se ha interrumpido ${ }^{28}$. De esta manera, en opinión de Piglia, la suspensión, el desvío, la postergación son narrados magistralmente por Kafka, autor que encarnaría a la perfección la experiencia de la escritura sin fin, del que escribe sin cesar y sin motivo, sin el objetivo concreto de convertirse en autor ${ }^{29}$.

En otro ensayo, habló Piglia de otro fenómeno literario que también debiéramos relacionar con todo esto: se trata de las novelas que no tienen fin, que duran lo que dura la vida del que escribe. «El tiempo que se emplea en escribirlas -afirma Piglia- forma parte de la textura de la obra y define su estructura. El libro crece en capas sucesivas, se va transformando; está escrito por escritores distintos a lo largo de los años; los manuscritos perdidos persisten en la obra, las diferentes versiones no se excluyen. (Varias novelas

27. E. Santos Unamuno, op. cit., pp. 70-71.

28. R. Piglia, El último lector, Barcelona, Anagrama, 2005, pp. 45-46.

29. Ibid., p. 66. 
en una)» ${ }^{30}$. En esta tradición podríamos ubicar la noción joyceana de work in progress, como dispositivo que nunca está fijo, así como el concepto de Juan Ramón Jiménez de Obra en marcha, con bastantes afinidades con el de Joyce, que se apoya también en una concepción de la Obra dinámica, en continua metamorfosis y por tanto nunca terminada, ya que sólo en el estado de realización logra alcanzar la anhelada perfección. Junto a Juan Ramón Jiménez, en España, Unamuno fue quizás uno de los autores que más reflexionaron sobre estas cuestiones. En Cómo se hace una novela (1927) plantea el asunto de la imposibilidad de dar fin a la obra: «Lo acabado, lo perfecto, es la muerte, y la vida no puede morirse. El lector que busque novelas acabadas no merece ser mi lector; él está ya acabado antes de haberme leído» ${ }^{31}$. Y más adelante: “¿Terminado? ¡Qué pronto escribí eso! ¿Es que se puede terminar algo, aunque sólo sea una novela, de cómo se hace una novela?» (p. 142). Pero quizás no haya habido ningún otro escritor más obsesionado por esta cuestión que Macedonio Fernández, el cual empezó a escribir Museo de la novela de la Eterna en 1904 y la prolongó hasta su muerte, durante casi cincuenta años. También la novela perfecta es para él la nunca concluida, la obra siempre en realización. No concibe la obra como orden cerrado y, al igual que Unamuno, sólo escribe para lectores que no busquen desenlaces, dedicando además su obra al «lector salteado». Pero Macedonio Fernández añade un dato importante y es que, a su parecer, en contra de lo aparente, ninguna novela está tan concluida como la suya, «escrita del todo antes del fin y no dejando a la vista ningún seguir» ${ }^{32}$. De nuevo nos encontramos ante la disyuntiva silencio/escritura infinita, pues sólo renunciando a escribir la novela o nunca terminándola se puede conseguir ese anhelo de completar la representación del mundo.

Muchos otros ejemplos se podrían aducir como manifestaciones literarias de ese mito de la "novela infinita», cuya concepción excluye la posibilidad de darle fin, ya que debe durar lo que dura la vida de quien la escribe, incluyendo todas las variantes y todos los desvíos. Piglia, además de la de Macedonio Fernández, se refiere a novelas como Adán Buenosayres de Marechal, Finnegans Wake de Joyce, El hombre sin atributos de Musil o Bajo el volcán de Lowry ${ }^{33}$. También la narrativa contemporánea universal de las últimas décadas nos ha seguido dando muestras magistrales de semejante anhelo. Probablemente uno de los ejemplos recientes más llamativos,

30. R. Piglia, Formas breves, Barcelona, Anagrama, 2000, p. 96.

31. M. de Unamuno, Cómo se hace una novela, Madrid, Alianza, 2004, p. 126.

32. M. Fernández, Museo de la Novela de la Eterna (ed. de Fernando Rodríguez Lafuente), Madrid, Cátedra, 1995, p. 187.

33. R. Piglia, Formas breves, op. cit., p. 96. 
extremo y eficaz de multiplicidad del relato hacia el infinito lo constituye la celebradísima novela del escritor norteamericano David Foster Wallace, titulada precisamente La broma infinita (1996). Se trata de la novela más múltiple y abarcadora que pudiéramos imaginar. Conceptos como los de principio o fin del relato parecen estar ausentes de esta ambiciosa obra de 1208 páginas (en su edición española), donde el relato se ramifica de manera extraordinaria en multitud de contenidos heterogéneos. No casualmente ha señalado la crítica que «quizás en el afán de multiplicidad Foster Wallace haya sabido llegar a un extremo que el escritor italiano [Italo Calvino] ni siquiera sospechó» ${ }^{34}$.

Evidentemente, no se pretende aquí agotar los ejemplos de multiplicidad en la literatura contemporánea, tan sólo evidenciar que el mito de la escritura infinita que tantas veces es revisado por Vila-Matas en su obra ha sido asunto esencial en la narrativa contemporánea más arriesgada y prometedora ${ }^{35}$.

34. J. F. Ferré, «Múltiples anulaciones: el ingenio infinito de David Foster Wallace», The Barcelona Review, 36, mayo-junio 2003 (http://www.barcelonareview.com/36/s_jff.htm) [en línea].

35. Del empeńo por parte de algunos escritores en escribir el libro infinito se ha pasado a convertir este en el tema de algunas obras contemporáneas (por supuesto, no infinitas). Es el caso de la novela de Michel Chabon, Chicos prodigiosos (1995), llevada al cine por Curtis Hanson. El protagonista de esta obra es un novelista atormentado durante muchos años en la escritura de una larguísima novela que no consigue nunca terminar. Significativamente, los miles de páginas que la componen vuelan y se pierden por los aires por culpa del viento, imposibilitándole ya definitivamente a terminar su novela. De nuevo encontramos la metáfora de la escritura infinita a la que no se puede poner un punto final. Pero si este es el mito, la realidad es una cosa muy distinta: el personaje del novelista que creó Chabon está inspirado en un escritor real, el norteamericano Chuck Kinder, quien durante 25 años estuvo escribiendo una novela a la que efectivamente no lograba darle un fin, titulada Lunas de miel, inspirada en su propia vida y en la de su amigo el escritor Raymond Carver. Después de que Chabon publicara la suya, Chicos prodigiosos, en la que Kinder y su novela interminable se convertían en material para la ficción, Kinder terminó por fin su novela y la publicó en 2001. Es decir, el escritor norteamericano, al igual que tantos otros (y pienso ahora en Vila-Matas poniendo irremediablemente fin a su novela infinita de los bartlebys), que se había elevado a ojos de Chabon a la categoría de escritor mítico por ese heroico empeño de escribir y escribir sin descanso, tuvo que hacer una concesión y cerrar su mítica novela. (Aprovecho esta nota para agradecer a Javier García Rodríguez sus puntuales informaciones sobre este asunto, así como tantas sugerencias para la realización de este y otros trabajos. Sobre el caso de Chuck Kinder, véase el «relato» de J. García Rodríguez: «El día que conocí a David Foster Wallace (respuesta al Acertijo pop 9)», en José Ángel Gayol (ed.), Nuevas maneras de contar un cuento, Gijón, Libros del Pexe, 2005, p. 160). 


\section{Caminos hacia lo infinito en la obra de Enrique Vila-Matas}

Efectivamente, Vila-Matas tiene muy presente en su obra toda esa tradición literaria precedente que se ha planteado el problema de la representación de la totalidad del universo y a través de sus personajes escritores la revisa más concienzudamente de lo que pudiera parecer a primera vista.

El asunto del comienzo y el fin de una novela, como puntos imposibles que limitan y falsean la realidad es abordado en numerosas ocasiones por los narradores escritores de sus obras. En Bartleby y compañía se habla de la cuestión Por dónde empezar una novela y sobre el comienzo imposible (pp. 50-52). Asimismo, en París no se acaba nunca cuenta el narrador que Marguerite Duras le preguntó por la novela que estaba escribiendo, a lo que éste ingenuamente le contestó que ya la había terminado. A Duras «esto le hizo mucha gracia, como si le asombrara o encontrara inverosímil que los libros pudieran tener un punto final» (p. 230). También en esta novela se cuenta la historia de Moll, joven heredero mallorquín que estaba escribiendo un libro infinito que le permitía «justificarse ante la muerte» (pp. 166-168). Pero es probablemente en su última novela, Doctor Pasavento, donde VilaMatas más ha ahondado sobre la cuestión de la fuga sin fin, de la escritura como un viaje sin retorno hacia el infinito. Morante afirma que ha escrito un microtexto que trata sobre «la desaparición de una certeza que hasta hace pocos ańos era entre nosotros inconmovible, la certeza de que todo tuvo que empezar en algún momento» (Doctor Pasavento, p. 107). Los personajes mantienen aquí una conversación acerca de cómo el arte contemporáneo ha cuestionado las nociones de principio y final y ha perdido la fe en los argumentos, al considerar que ningún fragmento de nuestra vida constituye una historia cerrada, con un argumento, con principio y con final. La literatura, afirma Morante, "consiste en dar a la trama de la vida una lógica que no tiene. A mí me parece que la vida no tiene trama, se la ponemos nosotros, que inventamos la literatura» (Doctor Pasavento, p. 103-104).

Pero Vila-Matas no sólo pone en boca de sus personajes diálogos en torno a esas viejas cuestiones como son el problema del principio y fin del relato, sino que también les hace poner en práctica (no olvidemos que la mayoría de sus personajes son novelistas) diferentes estrategias narrativas de representación de la totalidad del mundo, que con mayor o menor éxito han llevado a cabo distintos novelistas considerados experimentales. Me refiero sobre todo a la recomendación que el escritor francés Georges Perec (otro autor que sońó con representar la totalidad del mundo en su obra) hacía en su texto Tentativa de agotar un lugar parisino, de describir en su totalidad una calle cualquiera. El procedimiento aludido parece otra obsesión de 
Vila-Matas, y como tal reaparece numerosas veces en sus escritos. El personaje novelista de Extraña forma de vida está escribiendo una trilogía novelística sobre las vidas de la gente de su calle. Se trata de agotar un lugar concreto, al igual que proponía Georges Perec en su texto. En las crónicas tituladas «Tentativa de agotar la plaza de Rovira» y «Nueva tentativa de agotar la plaza Rovira» ${ }^{36}$ parte también el autor de las recomendaciones hechas en el texto citado de Georges Perec y acaba por considerarlo como «Un intento descriptivo que tiende a lo infinito y, por tanto, a todas luces imposible» ${ }^{37}$. Después de intentar hacer lo mismo que se propuso hacer Perec en la plaza de Rovira, concluye: «no sólo mi tentativa de apuntarlo todo ha fracasado, sino que me he quedado agotado. 13.32: me voy a casa a almorzar» ${ }^{38}$. Por su parte, el narrador escritor de Doctor Pasavento también se ve tentado a poner en práctica el procedimiento recomendado por Perec. En este caso, se trataba de comparar la rue Vaneau, en la que se ubicaba el Hotel parisino en el que se encontraba alojado, con el Paseo de San Juan de su infancia, después de ser ambos descritos en su totalidad (Doctor Pasavento, p. 170). Asimismo, en la crónica titulada "Ahí tienes una crónica», vuelve al asunto, y en este caso, mostrándose bastante irónico y escéptico con semejante procedimiento. Nos cuenta que, buscando un tema para su crónica, se le ocurrió la posibilidad de hacer «una crónica catálogo de las esquinas más peculiares de Barcelona». Plantea aquí casi en tono humorístico el quid de la cuestión: ante la frustración del escritor por su incapacidad de catalogar todas las esquinas de la ciudad (léase la totalidad del universo), debe conformarse con la más humilde tarea de hablar solamente de las esquinas más representativas, como única salida para no sentirse frustrado del todo ${ }^{39}$.

Vila-Matas pasa aquí revista a ciertos experimentos narrativos del grupo literario del que formaban parte Perec y Calvino ${ }^{40}$, que consistían

36. Ambas recogidas en Desde la ciudad nerviosa, op. cit., pp. 48-50 y 132-134, respectivamente.

37. E. Vila-Matas, «Tentativa de agotar la plaza de Rovira», art. cit., p. 48.

38. Ibid., p. 50.

39. E. Vila-Matas, «Ahí tienes una crónica», en Desde la ciudad nerviosa, op. cit., pp. 8486, p. 85. La curiosa estrategia de agotar un lugar cualquiera, de registrar todo lo que ocurre en un punto concreto del planeta, ha tenido frecuentes resonancias en la literatura y el arte contemporáneos. Un ejemplo extraordinario de esa tentativa la encontramos en la película Smoke (1995), de Wayne Wong, basada en un guión de Paul Auster. Allí veíamos cómo Auggie, empleado de un estanco en Brooklyn, dedicó cinco minutos todos los días durante más de 10 años a realizar su proyecto, la obra de su vida: fotografiar la misma esquina de su calle a la misma hora. El resultado eran más de cuatro mil fotografías del mismo sitio, que siendo todas iguales, era también cada una de ellas diferente a todas las demás.

40. Recordemos que el protagonista de El caballero inexistente, Agilulfo [de Italo Calvino], 
en enumerar los objetos, acumular todos los detalles del mundo, en una aspiración al infinito por adición. Se trataría de abrir bien los ojos ante el caos que envuelve al mundo y de registrarlo todo para luego intentar ordenarlo. Pero la actitud de Vila-Matas hacia este proyecto de totalidad enumeradora es de cierto distanciamiento irónico. Lo cierto es que ya el propio Calvino fue consciente de la imposibilidad de una totalidad enumeradora, al fin y al cabo oscilación dialéctica entre lo finito e infinito. En su ensayo «La máquina espasmódica», Calvino menciona el proyecto enciclopédico de Carlo Emilio Gadda (otro autor, por cierto, muy presente en el mundo narrativo de VilaMatas) y su inevitable frustración, así como el pesimismo gnoseológico resultante ${ }^{41}$. En esa práctica enumeradora, un hallazgo siempre conduce a otro y así hasta el infinito, pero el escritor siempre se tiene que detener en algún momento, de donde deviene la frustración, de la que también hablaba Vila-Matas.

Una nueva tentativa de libro infinito la encarna la peculiar estructura narrativa de su novela Bartleby y compañia, constituida por 86 notas a pie de página de un texto invisible, en las que se hace un rastreo e inventario de escritores con sindrome de Bartleby, de pulsión negativa o atracción por la nada. El propio Vila-Matas explica que hubo una organización cuidadosa de la trama y de su estructura, hecha de reglas, arbitrarias, pero rigurosas, que debían de conceder al diseño del libro «una fuerza centrífuga de gran libertad textual y con notable tendencia - no prevista por mí- al acto de creación continuo, inagotable, infinito» ${ }^{42}$. Una vez más, con cierto distanciamiento irónico hacia el plan estructural escogido, Vila-Matas pasa revista a otro tipo de modelo literario. Rápidamente se nos viene a la cabeza Pálido fuego de Vladimir Nabokov, constituida en buena parte por notas textuales, pero cabría pensar también en obras como el Diccionario Jázaro, de Milorad Pavic: la novela concebida como un diccionario o enciclopedia, cuya disposición externa se basa en el listado, en las entradas ordenadas que constituyen un corpus cerrado y limitado pero que aspira a representar

"combate su crisis de personalidad con una actitud enumeradora, como si se tratara de un hombre-máquina, una especie de calculadora» (E. Santos Unamuno, op. cit., p. 47).

41. E. Santos Unamuno, op. cit., pp. 79-80. Santos Unamuno revisa con detenimiento todos los trabajos donde Calvino trata de estas cuestiones. Llega a la conclusión de que en el autor italiano se combinan dos actitudes: «Si por un lado, se tiende a enumerar los objetos, a acumular los detalles del mundo, por otro resulta indispensable dar una forma al conjunto, escapar del infinito por adición que acecha en la actitud enumeradora, una aversión hacia el carácter ilimitado de un proyecto de enumeración exhaustiva» (Santos Unamuno, op. cit., p. 48).

42. E. Vila-Matas, «Un tapiz que se dispara en muchas direcciones», art. cit., pp. 193-194. 
el mundo. Es decir, estamos ante un claro ejemplo de la «poética de la totalidad» definida más arriba, una obra potencial, cuya estructura quiere funcionar metafóricamente como modelo de la totalidad del universo. Pero el autor tampoco se muestra excesivamente contundente sobre la eficacia de la estructura escogida en este caso. En una ocasión dice de su novela: «A mí me parece que Bartleby y compañia en ningún momento se debilita al final, sino todo lo contrario, sigue tan pujante como al comienzo; sigue pujante, entre otras cosas, porque su estructura es infinita, tal vez porque el texto comentado es invisible, no está en el libro, y nadie, por tanto, conoce su final» ${ }^{43}$. Pero al libro infinito el escritor ha de ponerle irremediablemente el punto final: «Precisamente fue al descubrir que Bartleby y compañia se abría a la creación inagotable cuando comprendí ya del todo que debía ponerle punto final, salvo que quisiera arriesgarme a que llegara un día, dentro de unos años, en que me aburriera del texto infinito y sintiera la tentación de redondearlo, de redondear lo que nunca se podría redondear ${ }^{44}$. Todo esto encierra cierta contradicción, que no deja de resultar frustrante. Así, en el mismo artículo, un poco después declara: «desde que di por terminado el libro y cerrado el inventario de escritores del No, voy sufriendo sin pena la aparición de nuevos bartlebys» ${ }^{45}$. Y en la entrevista antes citada, asume: "Se trata de un libro infinito y, por tanto, tenía que darle un final en el momento oportuno, que es lo que hice» ${ }^{46}$. El escritor se ve obligado a convertir su libro infinito en un breve muestrario de «escritores del No» de tan sólo 179 páginas, y Vila-Matas no sólo es muy consciente de esa contradicción sino que el mismo libro no hace otra cosa que hablar de ella.

Precisamente en sus últimas novelas, Vila-Matas parece ser más consciente que nunca de la imposibilidad de elaborar físicamente el Libro Total buscado por cualquier tipo de procedimiento enumerativo, pero esa toma de conciencia no le ha hecho cesar en la búsqueda. Nos referíamos antes a todos esos escritores que han hecho del extravío y la postergación, como estrategia en la representación de un tiempo ilimitado, un auténtico arte. Sin duda es este el camino más frecuentado en los últimos títulos de VilaMatas. En opinión de Ana Rodríguez Fischer, en Barlteby y compañia, y a pesar del aspecto externo de diccionario completo y cerrado, la errabundia, o, si se prefiere, «la felicidad del arte del extravío» (p. 57) parece ser la única

43. Ibid., p. 205.

44. Ibid.

45. Ibid., p. 195.

46. E. Vila-Matas, «Encuentro digital con Enrique Vila-Matas» (http://www.el-mundo. es/encuentros/invitados/2002/12/568/) [en línea]. 
ley compositiva ${ }^{47}$. Por supuesto, también los personajes de sus novelas reflexionarán mucho acerca de los principios que rigen la estrategia de ese extravío o vagabundeo narrativo sin rumbo fijo. Naturalmente, se trata de un camino que nunca se realiza en línea recta. En Bartleby y compañia se cita un texto de Laurence Sterne en su Tristram Shandy, donde nos dice que «en una narración el escritor no puede conducir su historia como un mulero conduce su mula -en línea recta y siempre hacia delante-, pues si es un hombre con un mínimo de espíritu se encontrará en la obligación, durante su marcha, de desviarse cincuenta veces de la línea recta para unirse a este o aquel grupo, y de ninguna manera lo podrá evitar» (pp. 153-154).

Hay en todas estas obras de Vila-Matas una clara y premeditada discontinuidad del discurso, interrumpido con frecuentes digresiones sobre cualquier cosa, que acaban por convertirse en la esencia del texto. En una reseña de El mal de Montano, Fernando Valls calificaba al autor de «trapecista que salta de un personaje a otro, de un género a otro» ${ }^{48}$. En su última novela, Doctor Pasavento, ese saltar de un lado a otro postergando siempre la conclusión se ha acentuado, evitando quizás más que nunca que el lector consiga imbuirse en la historia narrada. Ésta, salpicada de continuo de mil pequeños detalles marginales, acaba por perder toda importancia, dejando de ser así la justificación última del relato.

No casualmente, entre los numerosos escritores que Vila-Matas convierte en referentes continuos de su obra, tienen preferencia aquellos que se caracterizan por no tener un qué proponer, sólo un arte de vivir, aquellos que convierten la literatura en vida, por todos aquellos que sólo aspiran a escribir de lo pequeño, de lo que no tiene importancia, todas esas narraciones en las que no pasa nada o en las que pasan cosas aparentemente por casualidad, sin justificación ninguna. Sobre Robert Walser, a cuyo homenaje se dedica buena parte de la novela Doctor Pasavento, dice el narrador que es «El amo y señor del parloteo, de la escritura por la escritura» (Doctor Pasavento, p. 153). Encarna en su opinión al escritor que narra con absoluta y extrema ausencia de intención, el mejor representante de las novelas sin mensaje:

$\mathrm{Su}$ peculiaridad como escritor consistía en que nunca hablaba de sus problemas o de las cosas que le motivaban. Era un escritor sin motivo, alguien que escribía con una extrema

47. A. Rodríguez Fischer, «Las novelas peligrosas de Enrique Vila-Matas», Cuadernos hispanoamericanos, 635, mayo 2003, pp. 85-92.

48. F. Valls, «Don Quijote de las Azores o el último novísimo» [reseńa de E. Vila-Matas, El mal de Montano, Barcelona, Anagrama, 2002], Quimera, 226, febrero 2003, pp. 68-69, p. 69. 
ausencia de intenciones, con una asombrosa ausencia de finalidades externas al texto mismo. De ahí que los miles de páginas que escribiera compusieran una obra indefinidamente dilatable, elástica, desprovista de esqueleto, un prolongado parloteo que escondía la ausencia de cualquier progreso del discurso (Doctor Pasavento, p. 206).

En definitiva, es precisamente la falta de intención, el devenir azaroso de la escritura, lo que la hace infinita. El novelista de El resplandor con el que comenzaba este artículo sería el caso extremo, siendo precisamente la total falta de asunto de su novela lo que le permitió llenar cientos de páginas. Por otro lado, no es de extrañar que los narradores escritores de Vila-Matas ensalcen una y otra vez a ese tipo de literatura que considera que cualquier acontecimiento, por muy cotidiano y banal que pudiera parecer, merece ser objeto de atención poética. Recordemos que ya los shandys de su Historia abreviada de la literatura portátil (1985) tan sólo llevaban en sus equipajes «obras miniaturizadas que reflejaban todas, sin excepción, su absoluto desdén hacia lo que se considera importante, grave, fundamental ${ }^{49}$. Toda la escritura de Vila-Matas parece llegar una y otra vez a la dolorosa conclusión de que el asunto en arte carece de valor artístico, de que, como decía Macedonio Fernández, «la invención de asuntos de arte es una de las máximas ociosidades, pues la vida rebosa de asuntos» ${ }^{50}$. De ahí que el asunto de la obra pueda o deba ser azaroso y arbitrario.

En realidad, muchas de las novelas de Vila-Matas, entre las que cabría destacar Doctor Pasavento, donde se encuentran esas interesantes reflexiones sobre Walser, parecen haber sido escritas poniendo en práctica el método del lápiz con el que el autor suizo escribió sus microgramas, condicionados por el tipo y tamaño de papel donde eran escritos. El texto o "parloteo elástico» de Robert Walser, nos recuerda el narrador de Doctor Pasavento, terminaba sin más problema cuando se acababa el papel. En definitiva, el principio poético y ético por el que se regía el autor tan admirado por Vila-Matas tenía que ver con el papel que el azar había puesto en sus manos (Doctor Pasavento, p. 259). Y es precisamente «el azar» otra de las constantes obsesiones de nuestro autor. En principio, parece ser el azar el que conduce ese extravío narrativo del que tanto gusta. Se parte así de la idea de que cualquier versión que se ofrezca de los fenómenos del mundo es aleatoria o complementaria de un número infinito de posibles versiones. En definitiva, una explicación

49. E. Vila-Matas, Historia abreviada de la literatura portátil, Barcelona, Compactos Anagrama, 2000, pp. 49-50.

50. M. Fernández, Museo de la Novela de la Eterna, op. cit., p. 254. 
puede oponerse a otra sin que una sea verdadera y la otra falsa (en una suerte de lo que el pensamiento filosófico denomina "pluralismo»). En la «Presentación» que ha escrito para la reciente edición de Los mejores cuentos de Sergio Pitol, explica esta idea con total claridad, cuando afirma que siempre $\mathrm{da}$ varias versiones de un mismo hecho, sobre todo si ese hecho pertenece a su vida íntima ${ }^{51}$. Si nos fijamos en sus novelas más populares y que más han contribuido a su reconocimiento - Historia abreviada de la literatura portátil, Bartleby y compañia, El mal de Montano, Doctor Pasavento-, observamos cómo el paso de un asunto a otro, de un shandy a otro, de un bartleby a otro, etc., nunca parece regirse por la idea de necesidad, sino de manera gratuita, por el mero azar ${ }^{52}$. Sin embargo, estamos ante otro de esos temas que parecen obsesionar al autor que, en este caso, se mueve en la disyuntiva, tampoco resuelta, entre el azar o la creencia en una extrańa conexión entre las cosas que, aun siendo misteriosa e inexplicable, pudiera existir.

A lo largo de la novela El viaje vertical se insiste mucho en la casualidad, el azar (p. 116), se habla de "la casualidad de las calles», refiriéndose el narrador a estas como "un lugar ideal para las casualidades que ofrece la vida moderna» (p. 66). En Doctor Pasavento se vuelve al mismo tema, pero en esta novela irrumpe la duda, pues el narrador parece haber llegado a la conclusión de que todo aquello que parecían meras coincidencias no eran en verdad casualidades, sino que en alguna parte debía de haber una extraña y misteriosa relación entre las cosas que sólo de cuando en cuando centellea dejándose ver: "Le hablé de la rue Vaneau y de las extrańas conexiones que había yo captado en ella. "Ahí sí que uno nota que podría ser que estuviera todo muy conectado. La rue Vaneau me parece un microcosmos de la tensión del mundo entero" "(Doctor Pasavento, p. 324, y vid. también p. 330). Es decir, frente al mero azar, la creencia en una secreta comunicación y relación entre las partes del universo. Pero la disyuntiva atañe también a una cuestión de estética y del arte de construir las novelas, de tal suerte que, frente a ese extravío narrativo donde es el azar el que conduce al narrador de un asunto a otro, cabría hablar de una estructura narrativa sólo aparentemente

51. Barcelona, Anagrama, 2005, pp. 7-38, p. 30. Como ya hemos visto más arriba, no es raro que Vila-Matas caiga en sus declaraciones en frecuentes contradicciones. Ello tiene que ver con esa continua estrategia de autoficción y ruptura de fronteras entre literatura y vida en la que queda inmersa toda su obra, y no sólo sus novelas. En definitiva, creo que la voz narradora de las crónicas, o incluso de las entrevistas, es premeditadamente tan ficticia, como la de sus novelas.

52. Vid. J. M. Pozuelo Yvancos, "Vila-Matas en su red literaria», Cuadernos de narrativa, Grand Séminaire, Universidad de Neuchâtel, 2 y 3 de diciembre de 2002, 7, diciembre 2002, pp. 31-43, p. 34 . 
desordenada. Así, en París no se acaba nunca, hablando el narrador de las instrucciones que le había dado Marguerite Duras para escribir una novela, se subrayan dos: unidad y armonía. Le pregunta el narrador a su amigo Raúl Escari al respecto y este le aclara: «No es cuestión ni de unidad ni de cierta tolerancia hacia las divagaciones. El asunto es más profundo o complejo de lo que parece. Que los párrafos se comuniquen entre ellos. Nada más ni nada menos» (p. 178).

En esta nueva disyuntiva sin resolver se enfrentan ahora dos principios: el «extravío» contra el orden y la sensatez. No olvidemos, y aquí radica la contradicción, que la escritura era para Vila-Matas la experiencia de un viaje sin retorno al fin de la noche, una fuga al infinito. Sin embargo, en su opinión, a Robert Walser es el miedo a perderse en una fuga sin fin, en una errabundia ilimitada, lo que le lleva al oficio de la escritura, que en realidad es también intento de ordenar el universo. También el protagonista de Extraña forma de vida, como nos recordaba Monmany en una lúcida reseña de este libro, decía estar marcado por «la búsqueda desesperada de un lugar, siquiera humildísimo, de un orden cualquiera: en un universo, en una oficina de seguros, en un asilo para escritores lunáticos, en la cárcel de una vida familiar..." ${ }^{53}$. Y es que, en última instancia, la escritura, como cualquier otra operación de arte, por mucho que quiera aparentar el desorden y caos del pensamiento, no deja de ser un intento de conferir una forma a lo que no la tiene. La escritura siempre será el ejercicio de una razón que intenta reducir las cosas a claridad discursiva.

En conclusión, el arte narrativo de Vila-Matas se nos revela como una escritura infinita que deambula por un intrincado laberinto ${ }^{54}$, abriendo y cerrando puertas sin cesar en torno al viejo asunto del futuro de la novela y el problema de la representación literaria. El autor nos hace transitar así por los extremos de una premeditada y permanente tensión dialéctica que constituye la base de su poética, entre el orden y el azar, lo cerrado y lo abierto, entre el silencio y la escritura sin fin.

53. M. Monmany, «Enrique Vila-Matas: el principio de la realidad», Ínsula, 620-621 (agosto-septiembre 1998), pp. 18-21, p. 20.

54. Señala Pozuelo Yvancos varias metáforas que podrían representar a la perfección toda la obra de Vila-Matas: la «red», el «tejido», el «laberinto» o «la que ejecuta Kafka en el Agrimensor de El castillo, con sus constantes entradas y salidas en un viaje que podría proyectarse hasta el infinito» (Pozuelo Yvancos, art. cit. p. 31). Subraya también las conexiones existentes entre su concepción literaria y el «tejido de links», o vínculos de Internet que nos permiten una navegación por un bosque de asociaciones «en que una idea o figura remite a otra por contigüedades cuya única necesidad, esto es su único entramado narrativo, es no tenerlo, dibujar su negación, deconstruyendo la historia como lo era tradicionalmente [...]» (Pozuelo Yvancos, art. cit., p. 35). 
La disyuntiva nunca queda resuelta y es probablemente esa falta de solución la que mantenga viva y muy vigente la trayectoria de este autor. En uno de sus artículos, Vila-Matas se interrogaba sobre sí mismo (por supuesto, sin llegar una vez más a ninguna respuesta concluyente), al tiempo que confesaba su vocación por mezclar teorías opuestas, y no hay mejor manera de terminar este artículo que recordando esas palabras en las que él mismo parece ver su escritura deambulando sin cesar entre los dos polos de esta eterna incógnita:

Siempre he querido saber si estaba con aquellos grandes escritores -Tolstoi, por ejemplo- para quienes la existencia tiene, a pesar de todas las angustias que nos crea, un sentido, una unidad. O bien con aquellos-Kafka, Beckett-que nos han revelado la insuficiencia e irrealidad de la vida, el sinsentido de ésta: todos esos escritores que nos han descubierto la imposibilidad de vivir, e incluso la imposibilidad de escribir, y que nos han puesto en contacto con la odisea moderna del individuo que no vuelve a casa y se pierde y se disgrega, experimentando la insensatez del mundo y lo intolerable que es la existencia ${ }^{55}$.

\section{Bibliografía citada}

Bolaño, Roberto, Los detectives salvajes, Barcelona, Anagrama, 1998.

Eco, Umberto, Obra abierta, Barcelona, Ariel, 1984.

Fernández, Macedonio, Museo de la Novela de la Eterna (ed. de Fernando Rodríguez Lafuente), Madrid, Cátedra, 1995.

Ferré, Juan Francisco, «Múltiples anulaciones: el ingenio infinito de David Foster Wallace», The Barcelona Review, 36, mayo-junio 2003 (http://www. barcelonareview.com/36/s_jff.htm) [en línea].

García Rodríguez, Javier, "El día que conocí a David Foster Wallace (respuesta al Acertijo pop 9)", en José Ángel Gayol (ed.), Nuevas maneras de contar un cuento, Gijón, Libros del Pexe, 2005, pp. 145-174.

Gómez Trueba, Teresa, «El mundo hecho pedazos: multiplicidad en la novela y el cine contemporáneos", ALEC. Anales de la Literatura Española Contemporánea, 31, 1, 2006, pp. 93-118.

55. E. Vila-Matas, "Aunque no entendamos nada», Cuadernos de narrativa, Grand Séminaire, Universidad de Neuchâtel, 2 y 3 de diciembre de 2002, 7 (diciembre 2002), pp. 11 25 , p. 15. 
Monmany, Mercedes, «Enrique Vila-Matas: el principio de la realidad», Insula, 620621 (agosto-septiembre 1998), pp. 18-21.

Mora, Vicente Luis, Reseña de Doctor Pasavento (http://vicenteluismora.bitacoras. $\mathrm{com} /$ )

Piglia, Ricardo, Formas breves, Barcelona, Anagrama, 2000.

- El último lector, Barcelona, Anagrama, 2005.

Pitol, Sergio, El arte de la fuga, Barcelona, Anagrama, 1997.

Pozuelo Yvancos, José María, "Vila-Matas en su red literaria», Cuadernos de narrativa, Grand Séminaire, Universidad de Neuchâtel, 2 y 3 de diciembre de 2002, 7, diciembre 2002, pp. 31-43.

Roas, David, "El silencio de la escritura (a propósito de Bartleby y compañía)», Cuadernos de narrativa, Grand Séminaire, Universidad de Neuchâtel, 2 y 3 de diciembre de 2002, 7, diciembre 2002, pp. 129-139.

Ródenas de Moya, Domingo, «La novela póstuma o el mal de Vila-Matas», Cuadernos de narrativa, Grand Séminaire, Universidad de Neuchâtel, 2 y 3 de diciembre de 2002, 7, diciembre 2002, pp. 141-158.

Rodríguez Fischer, Ana, «Las novelas peligrosas de Enrique Vila-Matas», Cuadernos Hispanoamericanos, 635, mayo 2003, pp. 85-92.

Santos Unamuno, Enrique, Laberintos de papel: Jorge Luis Borges e Italo Calvino en la era digital, Cáceres, Universidad de Extremadura, 2002.

Unamuno, Miguel de, San Manuel Bueno, mártir. Cómo se hace una novela, Madrid, Alianza, 2004 (1 $1^{\text {a }}$ ed.: 1966).

Valls, Fernando, «Don Quijote de las Azores o el último novísimo» [reseña a Enrique Vila-Matas, El mal de Montano, Barcelona, Anagrama, 2002], en Quimera, 226, febrero 2003, pp. 68-69.

Vila-Matas, Enrique, Historia abreviada de la literatura portátil, Barcelona, Anagrama, 1985.

- El viaje vertical, Barcelona, Anagrama, 1999.

- Bartleby y compañía, Barcelona, Anagrama, 2000.

- El mal de Montano, Barcelona, Anagrama, 2002.

- "Aunque no entendamos nada», Cuadernos de narrativa, Grand Séminaire, Universidad de Neuchâtel, 2 y 3 de diciembre de 2002, 7 (diciembre 2002), pp. 11-25.

- París no se acaba nunca, Barcelona, Anagrama, 2003.

- Desde la ciudad nerviosa, Madrid, Alfaguara, 2004 (1ª ed.: 2000).

- Doctor Pasavento, Barcelona, Anagrama, 2005.

- «Encuentro digital con Enrique Vila-Matas» (http://www.el-mundo.es/ encuentros/invitados/2002/12/568) [en línea]. 